\title{
BMP Signaling Is Necessary for Patterning the Sensory and Nonsensory Regions of the Developing Mammalian Cochlea
}

\author{
Takahiro Ohyama, ${ }^{1,6}$ Martin L. Basch, ${ }^{2}$ Yuji Mishina, ${ }^{4}$ Karen M. Lyons, ${ }^{5}$ Neil Segill, ${ }^{1,7}$ and Andrew K. Groves ${ }^{2,3}$ \\ ${ }^{1}$ Division of Cell Biology and Genetics, House Ear Institute, Los Angeles, California 90057, ${ }^{2}$ Department of Neuroscience, Department of Molecular and \\ Human Genetics, and ${ }^{3}$ Program in Developmental Biology, Baylor College of Medicine, Houston, Texas 77030, ${ }^{4}$ Department of Biologic and Materials \\ Sciences, University of Michigan, Ann Arbor, Michigan 48109, ${ }^{5}$ Department of Orthopedic Surgery, Department of Molecular, Cellular, and Developmental \\ Biology, and Department of Biological Chemistry, University of California, Los Angeles, California 90095, and ${ }^{6}$ Department of Otolaryngology and \\ 7Department of Cell and Neurobiology, Keck School of Medicine, University of Southern California, Los Angeles, California 90033
}

The mammalian inner ear detects sound with the organ of Corti, an intricately patterned region of the cochlea in which one row of inner hair cells and three rows of outer hair cells are surrounded by specialized supporting cells. The organ of Corti derives from a prosensory domain that runs the length of the cochlear duct and is bounded by two nonsensory domains, Kölliker's organ on the neural side and the outer sulcus on the abneural side. Although much progress has been made in identifying the signals regulating organ of Corti induction and differentiation, less is known about the mechanisms that establish sensory and nonsensory territories in the cochlear duct. Here, we show that a gradient of bone morphogenetic protein (BMP) signaling is established in the abneural-neural axis of the cochlea. Analysis of compound mutants of Alk3/6 type I BMP receptors shows that BMP signaling is necessary for specification of the prosensory domain destined to form the organ of Corti. Reduction of BMP signaling in Alk3/6 compound mutants eliminates both the future outer sulcus and the prosensory domain, with all cells expressing markers of Kölliker's organ. BMP4 upregulates markers of the future outer sulcus and downregulates marker genes of Kölliker's organ in cochlear organ cultures in a dose-dependent manner. Our results suggest BMP signaling is required for patterning sensory and nonsensory tissue in the mammalian cochlea.

\section{Introduction}

The mammalian cochlea has recently emerged as an excellent system to study pattern formation during development. The cochlea develops as a ventral outgrowth of the inner ear primordium and is initially patterned into several molecularly distinct domains. The central, prosensory domain is destined to give rise to the organ of Corti, the auditory organ of the inner ear that contains sensory hair cells and different types of supporting cells (Kelley, 2006, 2007). The prosensory domain is bounded by two nonsensory domains. The domain closest to the auditory ganglion, the neural side, is termed Kölliker's organ and will develop into the inner sulcus, whereas the domain on the opposite, abneural side of the prosensory domain will develop into the outer sulcus (see Fig. $1 \mathrm{H}$ ).

Although the signals that specify particular hair cell and supporting cell types within the organ of Corti and define their precise planar orientation are beginning to be defined (Kelley, 2007; Kelly and Chen, 2007), the earlier signals that establish the early

Received July 8, 2010; revised Aug. 27, 2010; accepted Aug. 28, 2010.

This work was supported by National Institutes of Health Grant DC006185 (A.K.G., N.S.) and P30 Core Grant DC006276 and by the House Ear Institute. We are very grateful to Juan Llamas, Welly Makmura, and Francesca Della Ripa for excellent technical assistance, to Suzi Mansour, Brigid Hogan, David Kingsley, Thomas Vogt, Guy Richardson, Matthew Kelley, and Robin Lovell-Badge for probes, and to Doris Wu for offering advice on paint-filling.

Correspondence should be addressed to either of the following: Takahiro Ohyama, House Ear Institute, 2100 West 3rd Street, Los Angeles, CA 90057, E-mail: tohyama@hei.org; or Andrew Groves, Baylor College of Medicine, BCM295, 1 Baylor Plaza, Houston, TX 77030, E-mail: akgroves@bcm.edu.

DOI:10.1523/JNEUROSCI.3547-10.2010

Copyright $\odot 2010$ the authors $\quad 0270-6474 / 10 / 3015044-08 \$ 15.00 / 0$ developmental domains of the cochlea are poorly understood. The Notch pathway has been proposed to specify the prosensory domain of the cochlea as a result of signaling by the Notch ligand Jagged1 (Brooker et al., 2006; Kiernan et al., 2006). However, we have shown recently that the prosensory domain is still induced and differentiates into hair cells and supporting cells in $R B P J \kappa$ (recombination signal-binding protein 1 for $\mathrm{J} \kappa$ ) conditional knock-out (CKO) mice that lack all canonical Notch signaling in the inner ear (Doetzlhofer et al., 2009), suggesting that other signals must be responsible for induction of the prosensory domain.

Bone morphogenetic proteins (BMPs) are good candidates for regulating development of sensory tissue in the cochlea. Bmp4 is expressed in all developing sensory organs in the chick ear ( $\mathrm{Wu}$ and Oh, 1996) and in the developing cristae of the mouse (Morsli et al., 1998). Moreover, Bmp4 is expressed adjacent to the developing prosensory domain of the cochlea in cells destined to become Hensen's and Claudius' cells of the outer sulcus (Morsli et al., 1998). Blockade of BMP signaling with the secreted BMP antagonist Noggin disrupts the formation of ear sensory tissue in chick embryos (Chang et al., 1999; Gerlach et al., 2000). BMP signaling also modulates the production of hair cells in cultured chick otocysts (Li et al., 2005; Pujades et al., 2006) and in organ of Corti explants (Puligilla et al., 2007).

Because Bmp4 is expressed in the cochlear duct from its earliest stages, we speculated that BMP signaling plays an early role in specifying the sensory and nonsensory regions of the cochlea. We tested the role of BMP signaling in cochlear development by an- 
E11.5
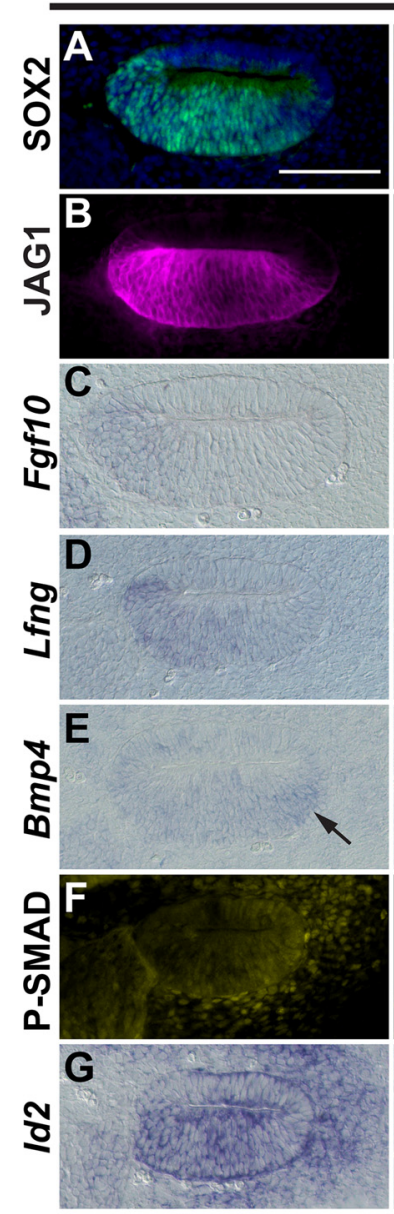

H

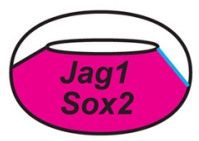

E12.5
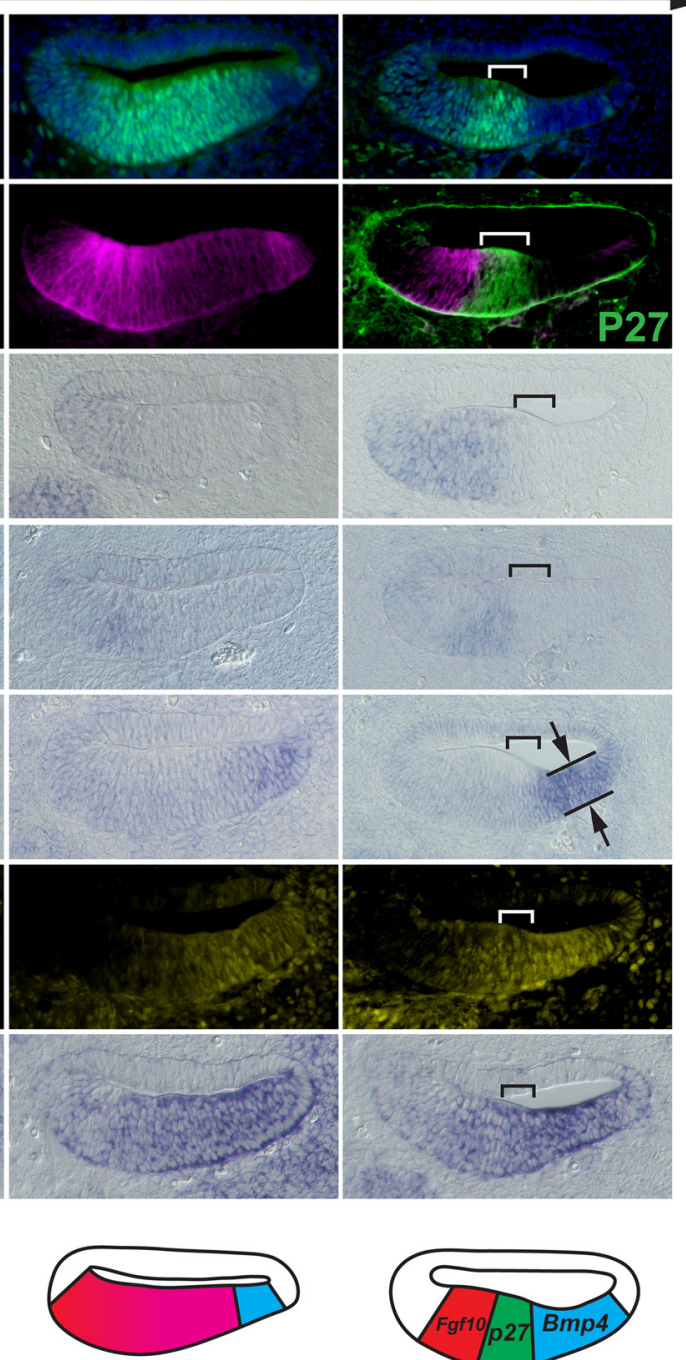

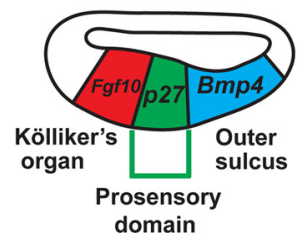

domain

Figure 1. Dynamic expression of molecular markers during mouse cochlear prosensory formation. $\boldsymbol{A}-\mathbf{G}$, Sections from E11.5 to E13.5 cochlear duct showing expression of S0X2 (A), JAG1 (B), P27 ${ }^{\mathrm{KIP1}}$ (green in $\boldsymbol{B}$ at E13.5), Fgf10 (C), Lfng (D), Bmp4 (E), phospho-SMAD1/5/8 $(\boldsymbol{F})$, and $I d 2(\boldsymbol{G})$. The approximate region of the prosensory domain at E13.5 is marked by brackets. $\boldsymbol{H}$, Schematic drawing summarizing the changes in expression of molecular markers that regionalize the E13.5 cochlear epithelium. The arrow in $\boldsymbol{E}$ indicates the region of Bmp4 expression. Note that the epithelium of the Bmp4 ${ }^{+}$domain at E13.5 is significantly thinner than other domains as indicated by the bars in $\boldsymbol{E}$. Scale bars, $100 \mu \mathrm{m}$.

alyzing compound mouse mutants for the Alk3 and Alk6 type I $\mathrm{BMP}$ receptors. We show that BMP signaling is necessary for the development of the outer sulcus and the prosensory domain. We also show that BMP4 suppresses markers of Kölliker's organ but promotes markers of the outer sulcus. We propose that establishing a gradient of BMP signaling is an important step in patterning the cochlea across its abneural-neural axis.

\section{Materials and Methods}

Mice. The following lines of mice were used in this study: Pax2-Cre (Ohyama and Groves, 2004), Alk3-null and Alk3-floxed (Mishina et al., 2002), and Alk6-null (Yi et al., 2000). To generate Alk3-CKO; Alk6 ${ }^{+-}$, Pax2-Cre mice are crossed with Alk3 ${ }^{+/-}$and $A l k 6^{+/-}$mice to generate Pax2-Cre ${ }^{+/-} ;$Alk $^{+/-} ;$Alk6 ${ }^{+/-}$animals. Alk $3^{\text {floxed/floxed }}$ mice were crossed with $A l k 6^{+/-}$mice and then intercrossed to generate $A l k 3^{\text {floxed/floxed }} ; A l k 6^{+/-}$ animals. These mice were crossed to generate Alk3-CKO; $\mathrm{Alk}^{+/-}$. The genetic background of these mice is a mixture of CD1 and C57BL/6. All mouse experiments were approved by the House Ear Institute Institutional Animal Care and Use Committee.

Bromodeoxyuridine incorporation assays. To analyze cell proliferation in the embryonic cochlea, pregnant mice were injected with bromodeoxyuridine (BrdU) on day 13 postcoitum following the procedure described by Lee et al. (2006). BrdU (10 mg/ml) was prepared in PBS and injected intraperitoneally three times with $2 \mathrm{~h}$ intervals at $50 \mu \mathrm{g} / \mathrm{g}$ body weight. Pregnant mice were killed $2 \mathrm{~h}$ after the last injection, and the embryos were isolated and fixed by immersion in $4 \%$ paraformaldehyde overnight.

In situ hybridization and immunohistochemistry. Embryonic day 12.5 (E12.5) to E15.5 heads were fixed in $4 \%$ paraformaldehyde in PBS overnight at $4^{\circ} \mathrm{C}$, sunk in $30 \%$ sucrose in PBS at $4^{\circ} \mathrm{C}$, incubated in Tissue-Tek O.C.T. compound (Sakura Finetek) at room temperature for 10 $\mathrm{min}$, and frozen on dry ice. Sections, $14 \mu \mathrm{m}$ thick, were cut using a Leica $3050 \mathrm{~S}$ cryostat. Digoxigenin-labeled antisense riboprobes were synthesized using standard protocols (Stern, 1998). The following probes were used: Bmp4 (clone identification number 4192158; Open Biosystems), Fgf10 (Suzanne Mansour, University of Utah, Salt Lake City, UT), Lfng (Thomas Vogt, Merck Research Laboratories, Boston, MA), Id2 (Matthew Kelley, National Institute on Deafness and Other Communications Disorders, Bethesda, MD), Sox2 (Robin Lovell-Badge, National Institute for Medical Research, London, UK), Bmp7 (Brigid Hogan, Duke University, Durham, UK), Bmp5 (David Kingsley, Stanford University, Palo Alto, CA), and Alk3 and Alk6 (Carl Heldin, Ludwig Institute for Cancer Research, Uppsala, Sweden). The in situ hybridization procedure was modified from a protocol by Domingos Henrique (Henrique et al., 1995). Detailed protocols are available on request. Antibodies used in this study were anti-BrdU (Fitzgerald), anti-JAG1 (Santa Cruz Biotechnologies), anti-MYO6 (Proteus), anti-P27 ${ }^{\mathrm{KIP} 1}$ (NeoMarker), anti-active CASPASE3 (R \& D Systems), anti-phospho-SMAD1/5/8 (Cell Signaling Technology), and anti-SOX2 (Millipore Bioscience Research Reagents). Fluorescently labeled secondary antibodies were from Invitrogen. For anti- P2 $7^{\mathrm{KIP} 1}$, JAG1, and SOX2 staining, sections were boiled for $10 \mathrm{~min}$ in $10 \mathrm{~mm}$ citric acid, $\mathrm{pH}$ 6.0. For anti-BrdU staining, cultures were hydrolyzed in $2 \mathrm{~N} \mathrm{HCl}$ for $10 \mathrm{~min}$. Cell nuclei were fluorescently labeled using $4^{\prime}, 6^{\prime}$-diamidino-2phenylindole (DAPI) (Invitrogen).

Paint-filling of mouse embryo ears. E13.5 embryos were fixed in Bodian's solution. Embryos were cut sagitally, and the brains were removed to expose the inner ears. The mouse heads were dehydrated by $100 \%$ ethanol and cleared in methyl salicylate. A $1 \%$ solution of high-gloss white enamel paint in methyl salicylate was injected into the inner ear duct through a pulled glass capillary needle (Sutter Instruments) with a Picospritzer II pressure injector (General Valve Corporation).

Organotypic cochlear culture and reverse transcription-PCR. Inner ear capsules of stage E11.5 embryos were collected in PBS (Invitrogen). To free the cochlear duct from surrounding condensed mesenchyme, tissue was incubated in calcium-magnesium-free PBS (Invitrogen) containing dispase $(1 \mathrm{mg} / \mathrm{ml}$; Invitrogen $)$ and collagenase $(1 \mathrm{mg} / \mathrm{ml}$; Worthington 

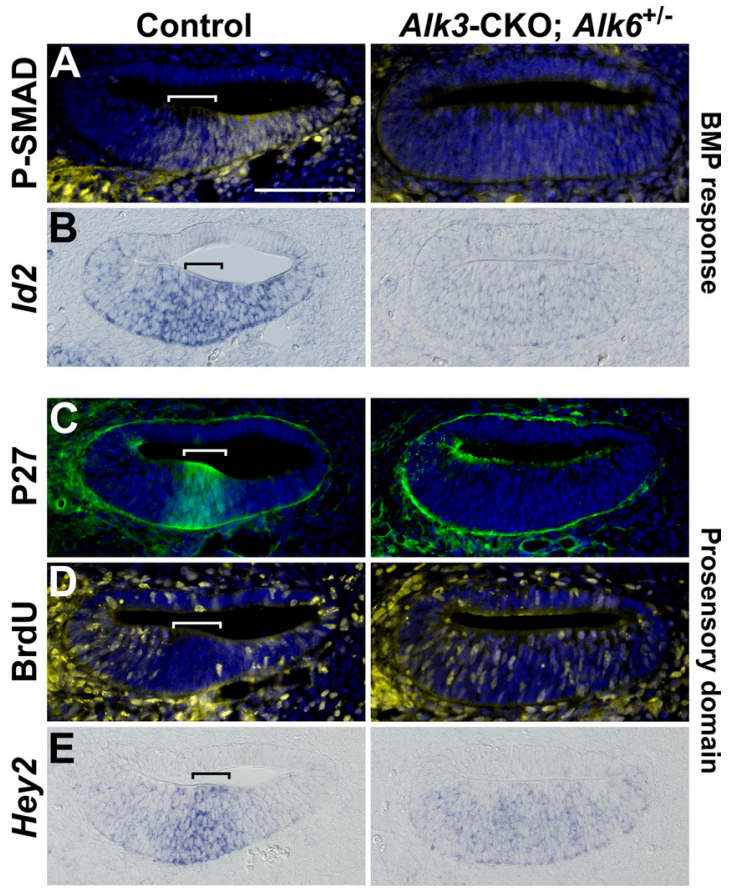

Figure 2. BMP signaling is necessary for prosensory specification in the mouse cochlea. $\boldsymbol{A}-\boldsymbol{E}$, Sections of the cochlear duct (mid-turn) from E13.5 embryos. Left, Control littermate. Right, Alk3-CKO; Alk6 ${ }^{+/-}$compound mutant. BMP signaling activity is almost completely reduced in mutant embryos, as revealed by phosphorylated-SMAD1/5/8 $(A)$ and the BMP4-responsive gene Id2 (B). Markers of the prosensory domain are absent in mutant embryos: $\mathrm{P} 27^{\mathrm{KIP} 1}(\boldsymbol{C})$, $\operatorname{BrdU}(\boldsymbol{D})$, and Hey2 $(\boldsymbol{E})$. The approximate location of the prosensory domain in control embryos is marked by brackets. Scale bar, $100 \mu \mathrm{m}$.

Biochemicals) as described previously (Doetzlhofer et al., 2004). To avoid contamination of the vestibular sensory organs, only the apical to mid-turn region of the cochlea was isolated with 30 gauge $1 / 2$ needles. Isolated cochlear explants (four per well) were cultured on SPI black membranes (SPI Supplies) in DMEM-F-12 (Invitrogen) with N2 supplement (Invitrogen) and $5 \mathrm{ng} / \mathrm{ml}$ epidermal growth factor ( $\mathrm{R} \& \mathrm{D}$ Systems). Cultures were maintained in a $5 \% \mathrm{CO}_{2} / 20 \% \mathrm{O}_{2}$ humidified incubator (Forma Scientific). BMP4 (R \& D Systems) was stored as a 10 mM stock in $4 \mathrm{~mm} \mathrm{HCl}, 0.1 \% \mathrm{BSA}$ at $-80^{\circ} \mathrm{C}$. For RNA extraction, total RNA from four explants was isolated using a Qiagen RNeasy Micro kit with QIAshredder. cDNA was synthesized using iScript (Bio-Rad). Quantitative PCR was performed with a PerfeCTA SYBR Green FastMix (Quanta) and gene-specific primer sets on a 7500 Real-time PCR Detection System (Applied Biosystems). Relative gene expression was analyzed using the $\Delta \Delta$ CT method (Livak and Schmittgen, 2001). Primer sets are listed in supplemental Table S1 (available at www.jneurosci.org as supplemental material).

\section{Results}

The developing cochlear duct is progressively patterned into three distinct domains

The mouse cochlea starts to develop as a ventral extension of the otocyst between 10 and 11 d of development (Morsli et al., 1998). The thickened region of cochlear duct initially expresses the transcription factor Sox2 and the Notch ligand Jagged 1 (Jag1) at E11.5 (Fig. 1 A,B). Bmp4 starts to be expressed asymmetrically in the abneural side of the cochlea from E11.5 (Fig. 1E, arrow) (Morsli et al., 1998). The cochlear duct shows additional evidence of asymmetry from the earliest point of its outgrowth; for example, Fgf10 and Lfng are expressed in the neural side of the cochlear duct from E11.5 onward, marking the future Kölliker's organ (Fig. 1C,D). After the onset of Bmp4 expression, the SOX2 ${ }^{+}$, $\mathrm{JAG}^{+}$cochlear duct becomes regionalized into three molecu- larly distinct compartments. From E12.5 onward, cells in the cochlea destined to form the organ of Corti express the cell-cycle inhibitor $p 27^{k i p 1}$ and exit the cell cycle, forming a region termed the prosensory domain (Chen and Segil, 1999; Lee et al., 2006). By E13.5, Sox2, which is necessary for the differentiation of sensory cells in the inner ear (Kiernan et al., 2005; Dabdoub et al., 2008) becomes restricted to the prosensory domain and part of Kölliker's organ destined to give rise to the inner sulcus of the cochlea (Fig. 1A), whereas JAG1 is progressively restricted to Kölliker's organ (Fig. $1 B$ ). The expression of Bmp4 in the abneural side of the sensory precursor domain progressively expands from E11.5 onward, marking the future outer sulcus characterized by a significantly thinner epithelium (Fig. $1 E$ ) that will include Hensen's and Claudius' cells (Morsli et al., 1998). Of the other BMP family members we tested (Bmp2, Bmp5, Bmp6, and $B m p 7$ ), $B m p 7$ is expressed ubiquitously at low levels in the cochlear epithelium at this stage, whereas expression of $B m p 2$, $B m p 5$, and Bmp6 could not be detected (supplemental Fig. S1, available at www.jneurosci.org as supplemental material) (Kiernan et al., 2005; Dabdoub et al., 2008).

We used antibodies to phosphorylated SMAD1/5/8 proteins to visualize BMP signaling in the cochlea. These SMAD proteins are phosphorylated by the serine-threonine kinase activities of Bmpr-Ia and Bmpr-Ib receptors and mediate transcriptional regulation of the BMP target genes by interacting with Smad4 (Kishigami and Mishina, 2005; Sieber et al., 2009). At E11.5, phospho-SMAD1/5/8 is detected at low levels throughout the cochlear epithelium (Fig. $1 F$, left). As the cochlea elongates, we observed the highest level of phospho-SMAD1/5/8 in the $B m p 4^{+}$future outer sulcus, a reduced level of SMAD phosphorylation in the prosensory domain, and the lowest levels in Kölliker's organ (Fig. 1 F, right) (supplemental Fig. S2, available at www.jneurosci.org as supplemental material). Expression of a known BMP target gene, Id2 (Hollnagel et al., 1999), appears to correlate well with phospho-SMAD levels in the cochlea at E13.5 (Fig. $1 F, G$, right). These results suggest that a gradient of BMP signaling across the abneural-neural axis of the cochlear duct is progressively established during cochlear outgrowth.

\section{BMP signaling is necessary for prosensory specification in the} mouse cochlea

To test the consequences of perturbing the BMP signaling gradient in the cochlea, we disrupted two BMP type I receptors, Alk3 (Bmpr-Ia) and Alk6 (Bmpr-Ib), in mice. Alk3 and Alk6 are expressed ubiquitously at low levels in the cochlear epithelium during prosensory specification (supplemental Fig. S1, available at www.jneurosci.org as supplemental material). Because Alk3 plays a crucial early role in the induction of mesoderm (Mishina et al., 1995), we conditionally inactivated Alk3 in the inner ear with Pax2-Cre mice (Mishina et al., 2002; Ohyama and Groves, 2004) to avoid premature lethality. Alk6 is not required for embryonic development, and we therefore used mice carrying an Alk6 null allele for our experiments (Yi et al., 2000).

Inner ear-specific Alk3/Alk6 double-mutant mice show no obvious cochlear structures by E12.5. Other structures, such as the semicircular canals and vestibular sensory epithelium, are missing or significantly reduced, suggesting that BMP signaling is necessary for early development and survival of otic epithelium (data not shown). However, loss of Alk3, together with a single copy of the Alk6 gene (Yi et al., 2000), reduced phospho-SMAD1/ 5/8 staining to barely detectable levels in the E13.5 cochlea (Fig. $2 A$ ) (supplemental Fig. S2, available at www.jneurosci.org as supplemental material). Expression of the BMP-responsive gene Id2 (Hollnagel et al., 1999) is also abolished (Fig. 2B). In the Alk3- 


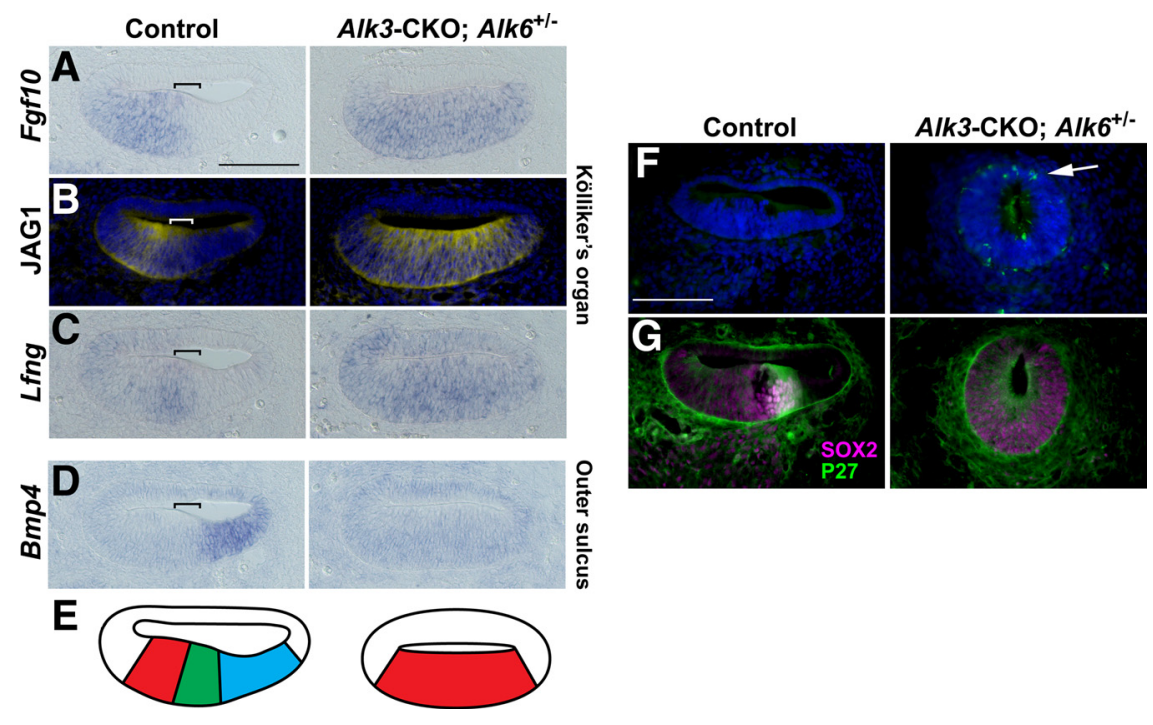

Figure 3. Markers of Kölliker's organ expand at the expense of the prosensory domain and the outer sulcus in Alk3-CKO; Alk6 ${ }^{+/-}$compound mutants. A-D, Sections of the cochlear duct (mid-turn) at E13.5. Left, Control littermate. Right, Alk3-CK0; Alk6 ${ }^{+/-}$compound mutant. Markers of Kölliker's organ such as Fgf10 $(\boldsymbol{A}), \mathrm{JAG1}(\boldsymbol{B})$, and $L \mathrm{fng}(\boldsymbol{C})$ are expressed throughout the dorsal cochlear duct of compound mutants, whereas Bmp4 (D), a marker of outer sulcus, is absent. The approximate location of the prosensory domain is marked by brackets. $\boldsymbol{E}$, A schematic drawing representing the phenotype of the Alk3-CKO; Alk6 ${ }^{+/-} \mathrm{com}^{-}$ pound mutant. In the Alk3-CKO; Alk6 ${ }^{+/-}$compound mutant, Kölliker's organ domain (red) expands at the expense of the prosensory domain (green) and the outer sulcus domain (blue). F, G, Sections of the cochlear duct (mid-turn) at E15.5.F, The arrow indicates apoptotic cells marked by activated CASPASE3 (green). Nuclei are labeled with DAPI (blue). G, P27 ${ }^{\text {KIP1 }}$ (green) and SOX2 (magenta) staining, showing an absence of the $\mathrm{p} 27^{\mathrm{kip} 1+}$ domain in the compound mutants. Scale bars, $100 \mu \mathrm{m}$.

CKO; $A l k 6^{+/-}$compound mutant cochlea, we saw no evidence for differentiation of the prosensory domain, which is normally marked by expression of $\mathrm{p} 27^{\mathrm{KIP} 1}$ (Fig. 2C). BrdU labeling of the E13 compound mutants showed that cells continued to proliferate throughout the cochlear duct, consistent with a lack of p $27^{\mathrm{KIP} 1}$ expression in the prosensory region (Fig. $2 \mathrm{D}$ ). The transcription factor Hey2, which is expressed strongly in the prosensory domain (Doetzlhofer et al., 2009), is significantly reduced in the compound mutant (Fig. 2 E). In compound mutant embryos, the majority of cochlear epithelium expressed markers of Kölliker's organ (Fgf10, Jag1, and Lfng) (Fig. 3A-C), whereas markers of the future outer sulcus $(B m p 4)$ were entirely absent (Fig. $3 D, E)$. As a result of greatly reduced BMP signaling in $A l k 3 ; A l k 6^{+/-}$ compound mutants, most cochlear duct cells undergo apoptosis at approximately E15.5 (Fig. $3 F$ ). We observed no evidence of hair cell differentiation in compound mutants on the basis of Myosin VI staining (data not shown), although SOX2 is expressed in most cochlear duct cells in compound mutants at low levels similar to the levels in wild-type Kölliker's organ (Fig. 3G). These results suggest that BMP signaling is necessary for the induction and survival of the prosensory domain that gives rise to the organ of Corti.

\section{BMP4 suppresses markers of Kölliker's organ and promotes prosensory and outer sulcus fates in a dose-dependent manner}

Because Alk3-CKO; Alk6 $6^{+/-}$compound mutants show barely detectable levels of BMP signaling in the cochlea and express markers of Kölliker's organ throughout the cochlear duct, it is not clear whether Kölliker's organ is induced by low levels of BMP signaling or actively repressed by high or moderate BMP levels. To test this, we cultured fragments of the cochlear duct from E11.5 mouse embryos in a defined medium containing different doses of BMP4 and measured RNA levels of different cochlear genes by reverse transcription-PCR after $2 \mathrm{~d}$. BMP4 downregulated expression of Kölliker's organ markers (Jag1, Fgf10, and Lfng) in cochlear cultures in a dosedependent manner (Fig. 4A). Addition of BMP4 to cochlear organ cultures also upregulated levels of known BMP target genes such as Id2 (Hollnagel et al., 1999), Lmxla (Chizhikov and Millen, 2004), and Lmo4 (de la Calle-Mustienes et al., 2003; Chang et al., 2008) in a dose-dependent manner (Fig. 4C) (supplemental Fig. S3, available at www.jneurosci.org as supplemental material). Ectopic expression of Id genes has been shown to inhibit hair cell differentiation (Jones et al., 2006). Because Id genes have been shown to negatively regulate transcription factors, including basic helix-loop-helix and Ets family members (Ruzinova and Benezra, 2003), BMP signals may act to inhibit Kölliker's organ and prosensory domain differentiation in the future outer sulcus through regulation of the $I d 2$ transcriptional repressor. Markers of the future outer sulcus such as $C v 2$ and Frzb (Qian et al., 2007), which are expressed between E14.5 and E15.5 (supplemental Fig. S3, available at www.jneurosci.org as supplemental material), are upregulated in $4 \mathrm{~d}$ cultures in the presence of BMP4 in a dose-dependent manner (Fig. 4D), suggesting that BMP4 promotes outer sulcus differentiation. We also tested whether BMP4 affects production of sensory hair cells by using Math1-green fluorescent protein (GFP) transgenic mice in which differentiating Math $1^{+}$sensory hair cells are marked by GFP (Lumpkin et al., 2003). Culture of Math1-GFP cochlear explants with BMP4 for $4 \mathrm{~d}$ revealed that the number of hair cells increased compared with controls at intermediate levels of BMP4 $(10 \mathrm{ng} / \mathrm{ml})$ but decreased with high levels of BMP4 $(50 \mathrm{ng} / \mathrm{ml})$ (Fig. $4 E$ ).

\section{Reduction in BMP signaling causes mild defects of vestibular morphology}

BMP signaling has been suggested to play a role in the formation of the cristae and semicircular canals (Chang et al., 2002, 2008; Blauwkamp et al., 2007; Omata et al., 2007; Hammond et al., 2009; Vervoort et al., 2010). To determine the effects of $A l k 3$ and Alk6 deletion on inner ear morphogenesis, we used paint-filling to analyze the morphology of Alk3-CKO and Alk3-CKO; Alk6 ${ }^{+/-}$ mutants at E13.5. Alk3-CKO mutants and $A l k 3^{+/-} ; A l k 6^{-1-}$ mutants showed no obvious morphological defects in the vestibular system but displayed a partially shortened cochlear duct (data not shown). Alk3-CKO; Alk6 $6^{+/-}$mutants had partially truncated and narrowed semicircular canals (Fig. 5B, arrowheads) and an even more severely truncated cochlear duct (Fig. $5 B$, asterisk). Although $B m p 4$ is expressed in vestibular sensory patches (Fig. 5A) (Morsli et al., 1998), vestibular sensory structures seem to develop normally in Alk3-CKO; Alk6 ${ }^{+/-}$mutants at E15.5 (Fig. 5C).

\section{Discussion}

The mammalian cochlea is one of the most intricately patterned tissues in any vertebrate. However, it is still essentially unknown which signals confer positional identity and polarity on the dif- 
ferent regions of the cochlea. Our current data suggests that BMP signaling is necessary for the induction of the prosensory domain that gives rise to the organ of Corti. However, this induction of the prosensory domain is only one manifestation of BMP signaling that also appears to specify the nonsensory regions on either side of the organ of Corti in a concentration-dependent manner.

A number of genes have been implicated in the development of the cochlear prosensory domain. The transcription factor Sox 2 is expressed in all developing prosensory regions of the ear and is necessary for their formation (Kiernan et al., 2005). Recent work suggests that Notch signaling is sufficient to induce ectopic vestibular sensory tissue but that Wnt signals, rather than Notch signals, may initiate this process in the early otocyst (Daudet and Lewis, 2005; Daudet et al., 2007; Jayasena et al., 2008). Notch signaling can also induce Sox2 expression in nonsensory regions of the cochlea (Dabdoub et al., 2008). Based on results from Jagged 1 conditional mutant mice, Notch signaling has been suggested to induce the prosensory domain in the mammalian cochlea (Brooker et al., 2006; Kiernan et al., 2006). However, we have shown recently that the prosensory domain and later hair cells and supporting cells are induced normally in conditional mutants of RBPJ $\kappa$, the transcriptional coeffector of canonical Notch signaling (Doetzlhofer et al., 2009). Together with our present results, we now propose that canonical Notch signaling serves to regulate hair cell and supporting differentiation through lateral inhibition (Kelley, 2006) but that $\mathrm{BMP}$ signaling is a more likely candidate to induce the prosensory domain of the cochlea.

\section{BMP signaling is necessary for sensory patterning of the mammalian cochlea}

BMPs are indispensable for a variety of cell fate decisions, such as those between neural and non-neural ectoderm, and for development of germ cells, lens, limb, and kidney (Dudley et al., 1995; Godin et al., 1999; Lawson et al., 1999; Nakayama et al., 2000; Liu and Niswander, 2005). A Drosophila homolog of Bmp2 and Bmp4, decapentaplegic (dpp), can act as a morphogen that patterns the wing imaginal disc and the dorsoventral axis of the early embryo, in which different levels of BMP signaling can specify neurogenic, ectodermal, or amnioserosa fates (O'Connor et al., 2006; Affolter and Basler, 2007). A variety of mechanisms, including positive feedback, degradation, and modulation of ligand diffusion and modulation by ligand binding proteins, have been proposed to contribute to the formation of distinct cell fates by signaling gradients (Mizutani et al., 2005; Wang and Ferguson, 2005; Lander, 2007; Serpe et al., 2008). Moreover, both qualitative and quantitative differences in BMP family signaling contribute to the patterning of the dorsal neural tube (Liem et al., 1995, 1997; Lee et al., 1998; Lee and Jessell, 1999; Liu and Niswander, 2005).
B
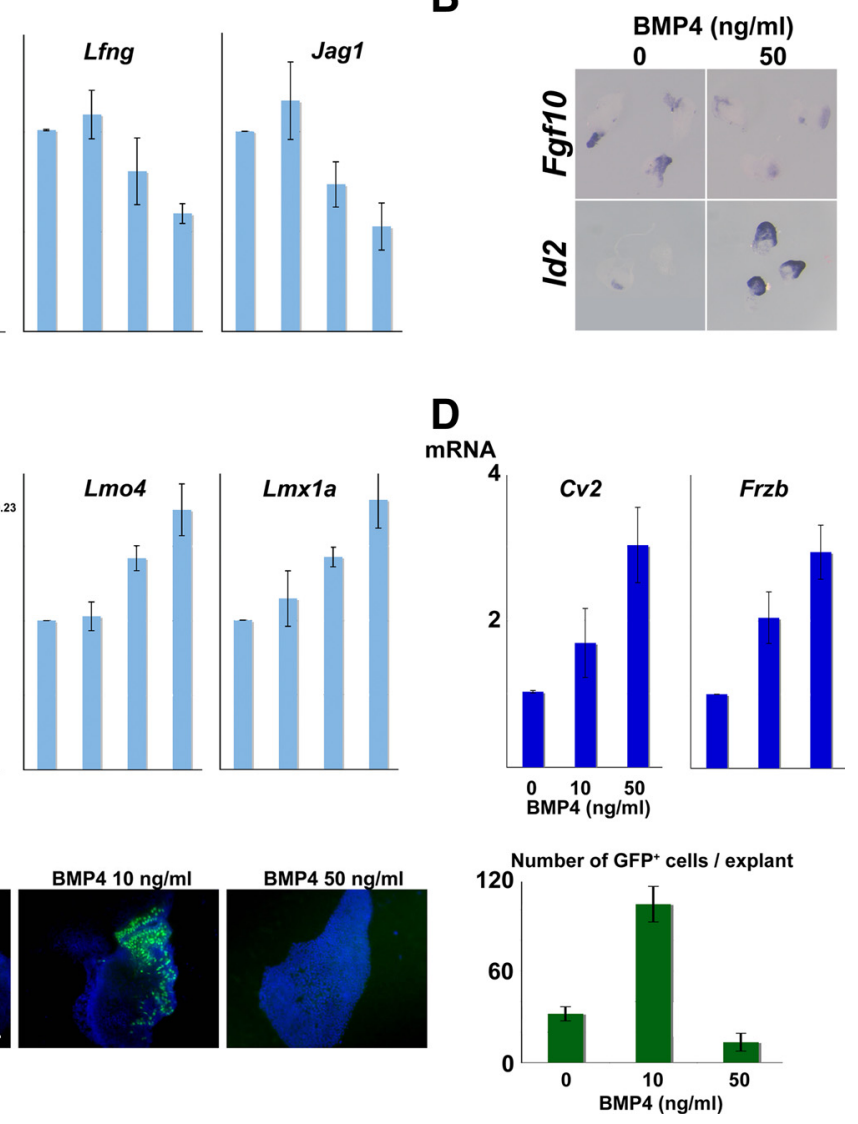

Figure 4. BMP4 represses Kölliker's organ gene expression and activates outer sulcus genes in a dose-dependent manner Quantitative $P C R$ analysis of $2 \mathrm{~d}$ cultures of $E 11.5$ cochlear explants with genes downregulated $(\boldsymbol{A})$ and upregulated $(\boldsymbol{C})$ by increasing concentrations of BMP4 protein $(n=4, \pm$ SEM). $B$, Whole-mount in situ hybridization of explants with Fgf10 and $/ d 2$ probes

Our results suggest that a BMP signaling gradient is required to pattern the mammalian cochlear sensory epithelium. First, $B m p 4$ is expressed on the abneural side of the cochlear duct, accompanied by a gradient of phospho-SMAD1/5/8 staining and a graded expression pattern of the BMP-responsive gene $I d 2$ (Fig. $1 F, G) . B m p 7$ is also expressed at lower levels throughout the cochlear duct, although it is not localized to any particular cell type (supplemental Fig. S1, available at www.jneurosci.org as supplemental material). We did not observe expression of other BMPs such as Bmp2 and Bmp5 (supplemental Fig. S1, available at www.jneurosci.org as supplemental material) in the cochlear epithelium at this stage. Second, greatly reduced BMP signaling in Alk3-CKO; Alk6 $6^{+/-}$mutant cochlea results in an expansion of the domain expressing Kölliker's organ markers (JAG1, Fgf10, and $L f n g$ ) at the expense of the prosensory and the outer sulcus domains (Figs. 2, 3). Interestingly, Bmp4 is itself downregulated in Alk3-CKO; Alk6 $6^{+/-}$mutants, suggesting that it may be regulated by positive feedback through BMP receptor signaling. Finally, activation of BMP signaling in cultured cochlear explants suggests that BMP4 promotes outer sulcus fates at the expense of Kölliker's organ (Fig. 4A-D), and intermediate levels of BMP signaling increase the number of sensory hair cells (Fig. 4E). Several recent studies have reported differing effects of BMP4 on the differentiation of hair cells. For example, addition of BMP4 to 

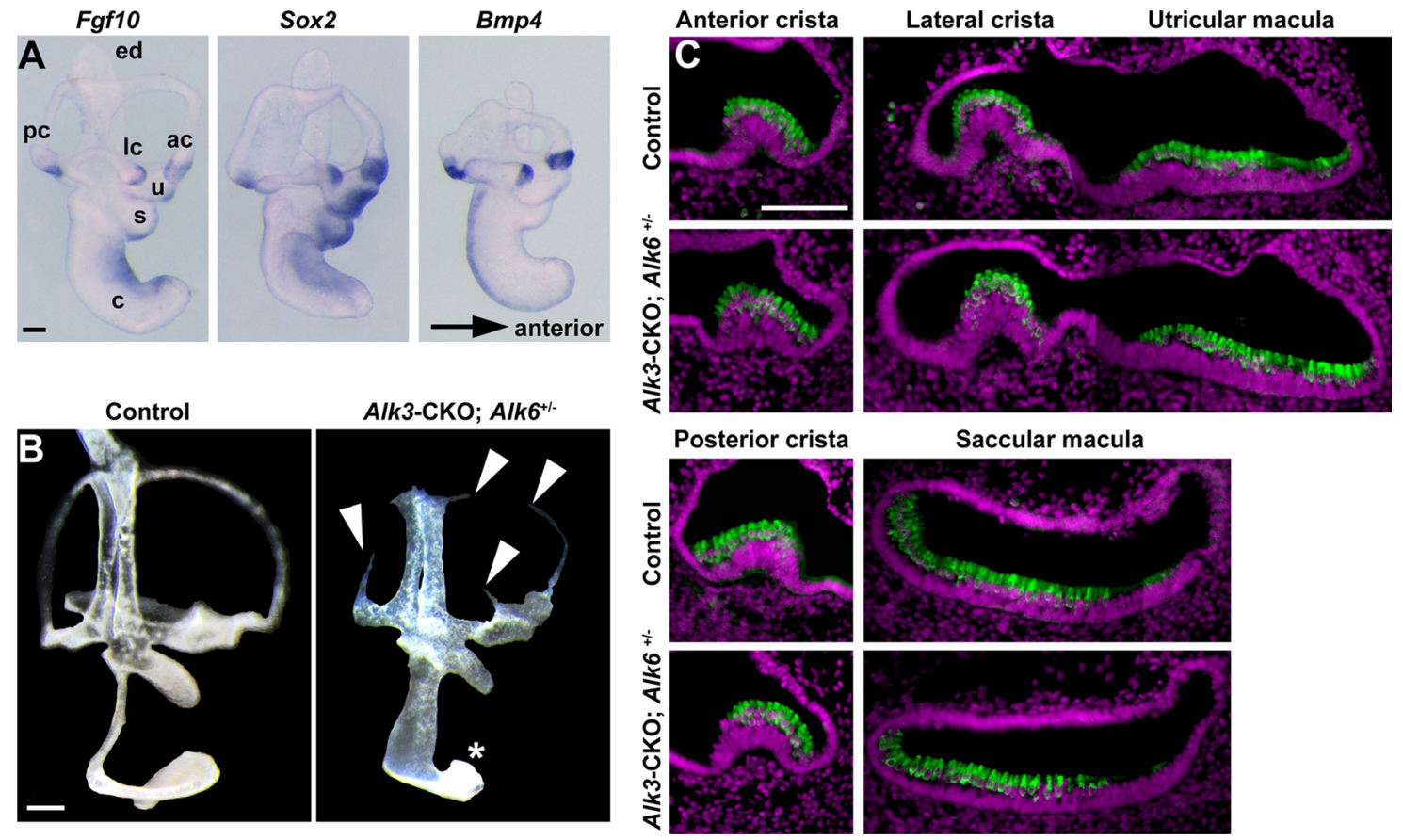

Figure 5. The gross morphology of the inner ear in BMP receptor mutants. A, Whole-mount in situ hybridization of the E12.5 inner ear, showing the expression of $F g f 10$, Sox2, and $B m p 4$. ac, Anterior crista; lc, lateral crista; pc, posterior crista; ed, endolymphatic duct; u, utricle; s, saccule; c, cochlea. B, Paint-fills of the E13.5 inner ears of control and Alk3-CKO; $A l k 6^{+/-}$mutants. The paint

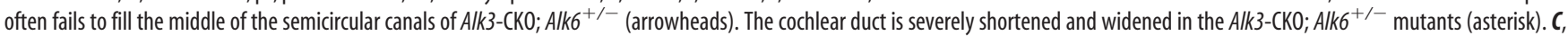
Vestibular sensory hair cell development revealed by Myosin VI staining (green) appears grossly normal in Alk3-CKO; Alk6 ${ }^{+/-}$mutants at E15.5. Nuclear staining by DAPI is indicated in magenta. Scale bars, $100 \mu \mathrm{m}$.

cultured otocysts from 3- to 4-d-old chick embryos can either induce (Li et al., 2005) or repress hair cell development (Pujades et al., 2006). One explanation for the differences between these studies that may be relevant to our results is that the two studies used different concentrations BMP4, with low concentrations of BMP4 promoting hair cell formation (Li et al., 2005) and higher concentrations of BMP4 being inhibitory (Pujades et al., 2006). Although it is likely that the hair cells produced in these studies were vestibular rather than auditory, our results in the cochlea confirm that BMP4 can elicit different levels of hair cell differentiation in a concentration-dependent manner. It is also possible that low or high doses of BMP4 may promote nonsensory fates in the bird or mammalian vestibular system, as we have shown for the cochlea. High doses of BMP4 have been shown to increase outer hair cell numbers in the organ of Corti (Puligilla et al., 2007), and mutation of Noggin, a secreted antagonist of BMP2 and BMP4, also leads to supernumerary hair cells (Hwang et al., 2010). However, both of these studies focused on times after formation of the prosensory domain and cell-cycle exit. It is therefore likely that the mechanism of BMP action in these studies is different from the events we report in Alk3-CKO; $\mathrm{Alk}^{+/-} \mathrm{com}-$ pound mutants, in which overt disruption of cochlear development is already evident between E12.5 and E13.5. Nevertheless, these studies suggest that BMP signaling may have additional roles in maintaining hair cell numbers after the specification of the prosensory domain, Kölliker's organ, and the outer sulcus by BMP4.

We propose a model in which a restricted domain of $B m p 4$ expression imparts patterning information to sensory precursor cells in the cochlear primordium from E11.5 onward. Initially, the cochlear duct consists of $J a g 1^{+}$; Sox $2^{+}$precursor cells (Fig. $1 A, B)$ that we hypothesize are multipotent and can give rise to Kölliker's organ, the prosensory domain, or the outer sulcus. Our data suggest that asymmetric expression of Bmp4 in the abneural region of this multipotent precursor domain locally suppresses Kölliker's organ fate at approximately E12.5 such that the precursor domain now contains a $\operatorname{Jag1} 1^{-}$, Sox $2^{-}, B m p 4^{+}$future outer sulcus domain (Fig. $1 \mathrm{H}$, middle) and a Jag1 ${ }^{+}$, Sox $2^{+}$Kölliker's organ/prosensory precursor domain. By E13.5, the cochlear epithelium is specified to form three different domains based on the graded levels of BMP signaling (Fig. $1 \mathrm{H}$, right). Based on this model, the greatly diminished levels of BMP signals in Alk3-CKO; Alk $6^{+/-}$compound mutants are unable to downregulate Kölliker's organ genes or specify the prosensory domain, and the entire cochlear epithelium differentiates into Kölliker's organ on the basis of the combined expression of JAG1, Fgf10, and Lfng (Fig. $3 E$ ). Although our results clearly suggest that BMP signaling is absolutely necessary for specification of the prosensory domain and outer sulcus, it is unclear whether intermediate levels of BMP signaling are sufficient to induce the prosensory domain. We could not detect a statistically significant increase of prosensory marker gene expression when E11.5 cochlear explants were incubated with the intermediate concentration of BMP 4 for $2 \mathrm{~d}$ (data not shown). It is possible that other factors such as FGF signaling are required in cooperation with BMP signaling to induce and maintain prosensory fate in culture (Pirvola et al., 2002). Additional analysis is required to understand the mechanisms of prosensory specification.

\section{Roles of BMP signaling in vestibular sensory structures}

BMPs are first expressed in the presumptive cristae and developing canal pouches of the inner ear (Morsli et al., 1998; Chang et al., 2002). Single knock-outs of Bmp2 and Bmp4 do not show severe early ear defects (Chang et al., 2008; Hwang et al., 2010), and no obvious inner ear defects have been reported in $B m p 7$ mutants (Dudley et al., 1995; Luo et al., 1995). However, only vestigial epithelial remnants of the ear are seen at E12.5 in Alk3- 
CKO; Alk6 $6^{-/-}$mutants (T.O., unpublished observations), suggesting that minimum levels of BMP signaling through both Alk3 and $A l k 6$ receptors are required for survival and proliferation of otocyst epithelium. Alk3-CKO; Alk $6^{+/-}$mutants develop inner ears with partial vestibular defects (Fig. 5), although much of the cochlear epithelium is lost by E15.5 (Fig. 3F, G). All Alk3-CKO, Alk3-CKO;Alk6 $6^{+/-}$, and Alk3-CKO;Alk6 ${ }^{-/-}$mutants die shortly after birth for reasons that are currently unknown. Conditional deletion of Bmp4 with either Foxg1-Cre or Pax2-Cre mice leads to more severe vestibular defects than those seen in our Alk3$\mathrm{CKO} ; A l k 6^{+/-}$mutants, accompanied by frequent loss of cristae and semicircular canals (Chang et al., 2008). This suggests that $B m p 4$ signaling through both Alk3 and Alk6 receptors is necessary for correct formation of the cristae and semicircular canals.

In conclusion, our data suggest that an asymmetric BMP signaling gradient is key to inducing and patterning the sensory domains of the mammalian cochlea. Additional understanding of the role of BMP signaling in cochlear development and a precise control of BMP signaling levels may enable more efficient generation of hair cells from pluripotent stem cells ( $\mathrm{Li}$ et al., 2003). We suggest the mammalian cochlea as an attractive system to understand the mechanisms of BMP signaling gradient in cell fate specification and asymmetric patterning of precursor cells during development.

\section{References}

Affolter M, Basler K (2007) The Decapentaplegic morphogen gradient: from pattern formation to growth regulation. Nat Rev Genet 8:663-674.

Blauwkamp MN, Beyer LA, Kabara L, Takemura K, Buck T, King WM, Dolan DF, Barald KF, Raphael Y, Koenig RJ (2007) The role of bone morphogenetic protein 4 in inner ear development and function. Hear Res 225:71-79.

Brooker R, Hozumi K, Lewis J (2006) Notch ligands with contrasting functions: Jaggedl and Deltal in the mouse inner ear. Development 133:1277-1286

Chang W, Nunes FD, De Jesus-Escobar JM, Harland R, Wu DK (1999) Ectopic noggin blocks sensory and nonsensory organ morphogenesis in the chicken inner ear. Dev Biol 216:369-381.

Chang W, ten Dijke P, Wu DK (2002) BMP pathways are involved in otic capsule formation and epithelial-mesenchymal signaling in the developing chicken inner ear. Dev Biol 251:380-394.

Chang W, Lin Z, Kulessa H, Hebert J, Hogan BL, Wu DK (2008) Bmp4 is essential for the formation of the vestibular apparatus that detects angular head movements. PLoS Genet 4:e1000050.

Chen P, Segil N (1999) p27(Kip1) links cell proliferation to morphogenesis in the developing organ of Corti. Development 126:1581-1590.

Chizhikov VV, Millen KJ (2004) Control of roof plate formation by Lmxla in the developing spinal cord. Development 131:2693-2705.

Dabdoub A, Puligilla C, Jones JM, Fritzsch B, Cheah KS, Pevny LH, Kelley MW (2008) Sox2 signaling in prosensory domain specification and subsequent hair cell differentiation in the developing cochlea. Proc Natl Acad Sci U S A 105:18396-18401.

Daudet N, Lewis J (2005) Two contrasting roles for Notch activity in chick inner ear development: specification of prosensory patches and lateral inhibition of hair-cell differentiation. Development 132:541-551.

Daudet N, Ariza-McNaughton L, Lewis J (2007) Notch signalling is needed to maintain, but not to initiate, the formation of prosensory patches in the chick inner ear. Development 134:2369-2378.

de la Calle-Mustienes E, Lu Z, Cortés M, Andersen B, Modolell J, GómezSkarmeta JL (2003) Xenopus Xlmo4 is a GATA cofactor during ventral mesoderm formation and regulates Ldb1 availability at the dorsal mesoderm and the neural plate. Dev Biol 264:564-581.

Doetzlhofer A, White PM, Johnson JE, Segil N, Groves AK (2004) In vitro growth and differentiation of mammalian sensory hair cell progenitors: a requirement for EGF and periotic mesenchyme. Dev Biol 272:432-447.

Doetzlhofer A, Basch ML, Ohyama T, Gessler M, Groves AK, Segil N (2009) Hey2 regulation by FGF provides a Notch-independent mechanism for maintaining pillar cell fate in the organ of Corti. Dev Cell 16:58-69.

Dudley AT, Lyons KM, Robertson EJ (1995) A requirement for bone mor- phogenetic protein-7 during development of the mammalian kidney and eye. Genes Dev 9:2795-2807.

Gerlach LM, Hutson MR, Germiller JA, Nguyen-Luu D, Victor JC, Barald KF (2000) Addition of the BMP4 antagonist, noggin, disrupts avian inner ear development. Development 127:45-54.

Godin RE, Robertson EJ, Dudley AT (1999) Role of BMP family members during kidney development. Int J Dev Biol 43:405-411.

Hammond KL, Loynes HE, Mowbray C, Runke G, Hammerschmidt M, Mullins MC, Hildreth V, Chaudhry B, Whitfield TT (2009) A late role for bmp2b in the morphogenesis of semicircular canal ducts in the zebrafish inner ear. PLoS One 4:e4368.

Henrique D, Adam J, Myat A, Chitnis A, Lewis J, Ish-Horowicz D (1995) Expression of a Delta homologue in prospective neurons in the chick. Nature 375:787-790.

Hollnagel A, Oehlmann V, Heymer J, Rüther U, Nordheim A (1999) Id genes are direct targets of bone morphogenetic protein induction in embryonic stem cells. J Biol Chem 274:19838-19845.

Hwang CH, Guo D, Harris MA, Howard O, Mishina Y, Gan L, Harris SE, Wu DK (2010) Role of bone morphogenetic proteins on cochlear hair cell formation: analyses of Noggin and Bmp2 mutant mice. Dev Dyn 239:505-513.

Jayasena CS, Ohyama T, Segil N, Groves AK (2008) Notch signaling augments the canonical Wnt pathway to specify the size of the otic placode. Development 135:2251-2261.

Jones JM, Montcouquiol M, Dabdoub A, Woods C, Kelley MW (2006) Inhibitors of differentiation and DNA binding (Ids) regulate Math1 and hair cell formation during the development of the organ of Corti. J Neurosci 26:550-558.

Kelley MW (2006) Regulation of cell fate in the sensory epithelia of the inner ear. Nat Rev Neurosci 7:837-849.

Kelley MW (2007) Cellular commitment and differentiation in the organ of Corti. Int J Dev Biol 51:571-583.

Kelly M, Chen P (2007) Shaping the mammalian auditory sensory organ by the planar cell polarity pathway. Int J Dev Biol 51:535-547.

Kiernan AE, Pelling AL, Leung KK, Tang AS, Bell DM, Tease C, Lovell-Badge R, Steel KP, Cheah KS (2005) Sox2 is required for sensory organ development in the mammalian inner ear. Nature 434:1031-1035.

Kiernan AE, Xu J, Gridley T (2006) The Notch ligand JAG1 is required for sensory progenitor development in the mammalian inner ear. PLoS Genet 2:e4.

Kishigami S, Mishina Y (2005) BMP signaling and early embryonic patterning. Cytokine Growth Factor Rev 16:265-278.

Lander AD (2007) Morpheus unbound: reimagining the morphogen gradient. Cell 128:245-256.

Lawson KA, Dunn NR, Roelen BA, Zeinstra LM, Davis AM, Wright CV, Korving JP, Hogan BL (1999) Bmp4 is required for the generation of primordial germ cells in the mouse embryo. Genes Dev 13:424-436.

Lee KJ, Jessell TM (1999) The specification of dorsal cell fates in the vertebrate central nervous system. Annu Rev Neurosci 22:261-294.

Lee KJ, Mendelsohn M, Jessell TM (1998) Neuronal patterning by BMPs: a requirement for GDF7 in the generation of a discrete class of commissural interneurons in the mouse spinal cord. Genes Dev 12:3394-3407.

Lee YS, Liu F, Segil N (2006) A morphogenetic wave of p27Kip1 transcription directs cell cycle exit during organ of Corti development. Development 133:2817-2826.

Li H, Liu H, Heller S (2003) Pluripotent stem cells from the adult mouse inner ear. Nat Med 9:1293-1299.

Li H, Corrales CE, Wang Z, Zhao Y, Wang Y, Liu H, Heller S (2005) BMP4 signaling is involved in the generation of inner ear sensory epithelia. BMC Dev Biol 5:16.

Liem KF Jr, Tremml G, Roelink H, Jessell TM (1995) Dorsal differentiation of neural plate cells induced by BMP-mediated signals from epidermal ectoderm. Cell 82:969-979.

Liem KF Jr, Tremml G, Jessell TM (1997) A role for the roof plate and its resident TGFbeta-related proteins in neuronal patterning in the dorsal spinal cord. Cell 91:127-138.

Liu A, Niswander LA (2005) Bone morphogenetic protein signalling and vertebrate nervous system development. Nat Rev Neurosci 6:945-954.

Livak KJ, Schmittgen TD (2001) Analysis of relative gene expression data using real-time quantitative PCR and the 2(-Delta Delta C(T)) method. Methods 25:402-408. 
Lumpkin EA, Collisson T, Parab P, Omer-Abdalla A, Haeberle H, Chen P, Doetzlhofer A, White P, Groves A, Segil N, Johnson JE (2003) Math1driven GFP expression in the developing nervous system of transgenic mice. Gene Expr Patterns 3:389-395.

Luo G, Hofmann C, Bronckers AL, Sohocki M, Bradley A, Karsenty G (1995) BMP-7 is an inducer of nephrogenesis, and is also required for eye development and skeletal patterning. Genes Dev 9:2808-2820.

Mishina Y, Suzuki A, Ueno N, Behringer RR (1995) Bmpr encodes a type I bone morphogenetic protein receptor that is essential for gastrulation during mouse embryogenesis. Genes Dev 9:3027-3037.

Mishina Y, Hanks MC, Miura S, Tallquist MD, Behringer RR (2002) Generation of Bmpr/Alk3 conditional knockout mice. Genesis 32:69-72.

Mizutani CM, Nie Q, Wan FY, Zhang YT, Vilmos P, Sousa-Neves R, Bier E, Marsh JL, Lander AD (2005) Formation of the BMP activity gradient in the Drosophila embryo. Dev Cell 8:915-924.

Morsli H, Choo D, Ryan A, Johnson R, Wu DK (1998) Development of the mouse inner ear and origin of its sensory organs. J Neurosci 18:3327-3335.

Nakayama T, Cui Y, Christian JL (2000) Regulation of BMP/Dpp signaling during embryonic development. Cell Mol Life Sci 57:943-956.

O'Connor MB, Umulis D, Othmer HG, Blair SS (2006) Shaping BMP morphogen gradients in the Drosophila embryo and pupal wing. Development 133:183-193.

Ohyama T, Groves AK (2004) Generation of Pax2-Cre mice by modification of a Pax2 bacterial artificial chromosome. Genesis 38:195-199.

Omata Y, Nojima Y, Nakayama S, Okamoto H, Nakamura H, Funahashi J (2007) Role of bone morphogenetic protein 4 in zebrafish semicircular canal development. Dev Growth Differ 49:711-719.

Pirvola U, Ylikoski J, Trokovic R, Hébert JM, McConnell SK, Partanen J (2002) FGFR1 is required for the development of the auditory sensory epithelium. Neuron 35:671-680.
Pujades C, Kamaid A, Alsina B, Giraldez F (2006) BMP-signaling regulates the generation of hair-cells. Dev Biol 292:55-67.

Puligilla C, Feng F, Ishikawa K, Bertuzzi S, Dabdoub A, Griffith AJ, Fritzsch B, Kelley MW (2007) Disruption of fibroblast growth factor receptor 3 signaling results in defects in cellular differentiation, neuronal patterning, and hearing impairment. Dev Dyn 236:1905-1917.

Qian D, Jones C, Rzadzinska A, Mark S, Zhang X, Steel KP, Dai X, Chen P (2007) Wnt5a functions in planar cell polarity regulation in mice. Dev Biol 306:121-133.

Ruzinova MB, Benezra R (2003) Id proteins in development, cell cycle and cancer. Trends Cell Biol 13:410-418.

Serpe MJ, Rivera M, Kersey FR, Clark RL, Craig SL (2008) Time and distance dependence of reversible polymer bridging followed by singlemolecule force spectroscopy. Langmuir 24:4738-4742.

Sieber C, Kopf J, Hiepen C, Knaus P (2009) Recent advances in BMP receptor signaling. Cytokine Growth Factor Rev 20:343-355.

Stern CD (1998) Detection of multiple gene products simultaneously by in situ hybridization and immunohistochemistry in whole mounts of avian embryos. Curr Top Dev Biol 36:223-243.

Vervoort R, Ceulemans H, Van Aerschot L, D’Hooge R, David G (2010) Genetic modification of the inner ear lateral semicircular canal phenotype of the Bmp4 haplo-insufficient mouse. Biochem Biophys Res Commun 394:780-785.

Wang YC, Ferguson EL (2005) Spatial bistability of Dpp-receptor interactions during Drosophila dorsal-ventral patterning. Nature 434:229-234.

Wu DK, Oh SH (1996) Sensory organ generation in the chick inner ear. J Neurosci 16:6454-6462.

Yi SE, Daluiski A, Pederson R, Rosen V, Lyons KM (2000) The type I BMP receptor BMPRIB is required for chondrogenesis in the mouse limb. Development 127:621-630. 